\title{
Influence of Clinical Knowledge, Organizational Context, and Practice Style on Transfusion Decision Making
}

\section{Citation}

Salem-Schatz, Susanne R. 1990. "Influence of Clinical Knowledge, Organizational Context, and Practice Style on Transfusion Decision Making." JAMA 264 (4) (July 25): 476. doi:10.1001/ jama.1990.03450040072034.

\section{Published Version}

doi:10.1001/jama.1990.03450040072034

\section{Permanent link}

http://nrs.harvard.edu/urn-3:HUL.InstRepos:32692592

\section{Terms of Use}

This article was downloaded from Harvard University's DASH repository, and is made available under the terms and conditions applicable to Other Posted Material, as set forth at http:// nrs.harvard.edu/urn-3:HUL.InstRepos:dash.current.terms-of-use\#LAA

\section{Share Your Story}

The Harvard community has made this article openly available.

Please share how this access benefits you. Submit a story.

\section{Accessibility}




\title{
Influence of Clinical Knowledge, Organizational Context, and Practice Style on Transfusion Decision Making
}

\section{Implications for Practice Change Strategies}

\author{
Susanne R. Salem-Schatz, ScD; Jerry Avorn, MD; Stephen B. Soumerai, ScD
}

\begin{abstract}
Evidence shows that blood prcducts, like other health care resources, are often used inappropriately, but the reasons for this have not been well studied. We conducted a face-to-face survey of 122 general surgeons, orthopedic surgeons, and anesthesiologists in three hospitals to evaluate the influence of several clinical and nonclinical factors on transfusion decision making. We found widespread deficiencies in physicians' knowledge of transfusion risks and indications. Each transfusion risk was estimated correctly by fewer than half of the physicians surveyed, and only $31 \%$ responded correctly to a set of four questions regarding transfusion indications. Attending physicians routinely had lower knowledge scores than did residents, yet they exhibited more confidence in their knowledge. Residents' transfusion decisions, however, were strongly influenced by the desires of their attending physicians, resulting in their ordering potentially inappropriate transfusions. Of the residents surveyed, $61 \%$ indicated that they ordered transfusions that they judged unnecessary at least once a month because a more senior physician suggested that they do so. These findings provide insights for the development of strategies to improve transfusion practices, which would address the dual concerns of quality of care and cost containment.
\end{abstract}

(JAMA. 1990;264:471-475)

UNDERSTANDING how to optimize physicians' treatment decisions is an increasingly important dimension of quality assurance and cost containment efforts. Despite numerous efforts to improve the use of a variety of clinical resources, evidence documenting inappropriate use of hospital resources continues to grow. One clinical practice for which studies have repeatedly documented inappropriate use is the transfusion of blood products. ${ }^{1-3}$ The most recent studies, as well as the conclusions of a 1988 National Institutes of Health Consensus Conference on perioperative red blood cell transfusion, indicate that this problem continues despite widespread concern about the potential for transfusion-induced disease. ${ }^{+, \hat{\sigma}}$

The importance of understanding and improving transfusion decision making is further heightened by concern about the adequacy of the blood supply during the next decade. Constraints on the

From the Program for the Analysis of Clinical Strategies and the Department of Social Medicine, Harvard Medical School and Beth Israel Hospital, Boston, Mass. Reprint requests to Program for the Analysis of Clinical Strategies, 333 Longwood Ave, Boston, MA 02115 (Dr Salem-Schatz). blood supply are growing because of a number of factors, including the increasing frequency of blood-intensive procedures, the aging of the US population (the elderly both donate less and receive more blood products), and decreased donation due to restrictions on donor eligibility and an increase in the number of tests to screen out potentially contaminated units. Transfusion of blood products is thus an attractive target for achieving improvements in the quality of care while conserving a scarce resource and reducing health care costs.

Despite the evaluation of numerous intervention strategies, there is no consensus on the best way to improve suboptimal clinical decision making. One explanation for the inconsistent results of various intervention strategies is that the success of such efforts may depend heavily on the nature of the targeted clinical practice and the social structure of the practice setting, in addition to the specific strategy chosen (eg, education or feedback). ${ }^{6-10}$ It is, therefore, important to evaluate the influence of clinical knowledge and nonclinical factors on physicians' transfusion de- cisions before developing an intervention strategy.

\section{CLINICAL INFLUENCES ON TRANSFUSION DECISION MAKING}

Physician knowledge about transfusion indications and risks includes an understanding of causal clinical relationships and assessments of probabilities. Knowledge may vary systematically among groups of physicians. For instance, physicians in teaching hospitals with strong medical school affiliations might be expected to be more knowledgeable than those in hospitals with less rigorous training components. Differences may also be related to physician age; the recently increased emphasis on transfusion medicine in the clinical curriculum may result in younger physicians being more aware of transfusion-related science.

Although physicians' assessments of transfusion-associated risk probabilities may be retained as clinical "facts," their perceptions may also be influenced by their clinical experience. ${ }^{11-13}$ For instance, the "availability heuristic" described by Tversky and Kahneman ${ }^{14}$ suggests that the assessment of the probability of an event is dependent on the ease with which relevant events can be recalled. Thus, a physician who recently cared for a patient with posttransfusion hepatitis might be expected to give a higher estimate of the probability of this outcome than would a physician with no such experience.

\section{NONCLINICAL INFLUENCES ON TRANSFUSION DECISION MAKING}

A variety of nonclinical influences are also relevant to the study of transfusion decision making. Physicians' decisions are influenced by their colleagues through professional and social networks. ${ }^{15-17}$ The influence of peer pressure is felt most strongly when several physicians practice together, such as in 
group practice or among hospital house staff. $^{8}$ In these settings, actions may at times be motivated by the expectation of a superior or influential peer, a desire to conform with group norms, or the wish to avoid criticism. ${ }^{7,18-20}$

Transfusion decisions might also be modified in response to patient preferences. Widespread patient concern over the potential for transmission of the human immunodeficiency virus through blood products is likely only to increase with the implementation of informed consent procedures for blood transfusion. Cost considerations are generally reported to have little influence compared with clinical factors, ${ }^{21}$ although they may be more important in decisions regarding the use of expensive tests and treatments. ${ }^{22}$ Perceptions of resource availability may also play a role. ${ }^{23}$

Other important influences on decision making are a function of practice style or the physician's "clinical personality." One dimension of practice style is the degree of interventionism in a physician's approach to medical care; intervention-oriented physicians are more inclined toward immediate action and may have a higher tolerance for the undesirable consequences of therapy itself. ${ }^{24}$ Similarly, some physicians may be predisposed to provide treatments because of a preference for errors of commission vs errors of omission. Haney $^{25}$ suggested that the traditional injunction Primum non nocere ("First do no harm") may often be suspended in favor of the rule "First do something." Such a propensity to act may be a factor in explaining inappropriate transfusion practice. Decision making may also be influenced by the physician's level of confidence about relevant clinical knowledge; this confidence may also indicate a receptiveness to new information that may be inconsistent with their current beliefs. ${ }^{26,27}$

\section{SUBJECTS AND METHODS}

In preparation for a program to improve the use of blood products, we conducted a survey to assess physicians' knowledge of the risks of and indications for red blood cell transfusion, their perceptions of the importance of nonclinical factors, including resource availability, peer influence, cost, and hospital guidelines, and the "practice style" dimensions of confidence and interventionism. Questions pertaining to knowledge of transfusion indications and risks were written and scored with the assistance of a panel of experts in transfusion medicine. The survey instrument was pretested on six surgical residents and five attending physicians to reveal inconsis- tent or confusing questions and was revised accordingly.

\section{Sample}

Physicians practicing in three hospitals in a large northeastern city participated in the study. Hospital A was the primary teaching hospital of an academic medical center. Hospital B was a municipal hospital with its own attending physicians, whose residents rotated in from a major teaching hospital. Hospital $\mathrm{C}$ was a secondary teaching hospital with its own residency program and no strong medical center affiliation. Hospitals were randomly selected from inclusive lists of each of these three hospital types. Each institution was requested to provide a list of all currently active attending physicians and residents in the specialties of general surgery, orthopedic surgery, and anesthesiology, reflecting our focus on perioperative red blood cell transfusion. Physicians on these lists who had been practicing in the hospital during the previous academic year (1985-1986) were approached to participate in the study. Letters from service chiefs encouraging participation were followed by telephone calls from project staff to set up interviews. Follow-up calls were made until an appointment was made or the physician specifically refused to participate.

\section{Survey Administration}

Interviews were conducted by one of us (S.R.S.-S.) or another trained interviewer. Questions were read aloud by the interviewer, and physicians responded either in writing on their copy of the survey or verbally, according to their preference. The interviewers did not read clinical case descriptions aloud, nor did they read questions where there might be the perception of a socially desirable response; only written responses were given to these questions. Interviews took an average of $50 \mathrm{~min}$ utes to complete.

\section{Measures of Clinical Knowledge}

Knowledge of Transfusion Indications.-Measures of knowledge of transfusion indications were based on three sets of questions. The decision component question asked physicians in an open-ended manner to indicate what information they would consider most important in deciding whether to order a red blood cell transfusion before an elective hip replacement in an uncomplicated case, described in a brief case description. When "heart disease" was given as a response, physicians were prompted to specify current heart disease, a history of heart disease, or both.
The decision component question was as follows:

A patient has been admitted to your service for an elective hip replacement. You take the patient's medical history, conduct a thorough physician examination, and obtain the relevant laboratory tests. What pieces of information would you consider to be most important in determining whether or not to order a red blood cell transfusion preoperatively?

Responses on this question were scored as follows: 4 points if hematocrit and current heart disease were mentioned, 3 points for hematocrit and a history of heart disease, 2 points for hematocrit and no mention of heart disease, and 1 point for heart disease and no mention of hematocrit.

Physicians were next asked to review a set of patient management vignettes and make a transfusion decision. In four cases the most appropriate response was not to transfuse, and in one a transfusion was indicated. Since the primary purpose of this study was to understand the determinants of overtransfusion, only the cases in which transfusion was unnecessary were included in the analysis. A sample patient management vignette follows:

A 62-year-old man with advanced carcinoma of the prostate metastatic to bone is referred to you for evaluation. Since his diagnosis 1 year ago, his clinical course has deteriorated rapidly, with increasing bone pain, lethargy, and severe depression. During the last five visits to his primary care physician, his hematocrit has varied between 0.30 and 0.33. In his consultation with you, he reports a progressive feeling of weakness over the last several months, worse now than ever before, "to the point where I don't feel like getting out of bed anymore." A bone marrow examination performed recently revealed extensive replacement of marrow by tumor cells. His current medications include diazepam (Valium), $5 \mathrm{mg}$ three times daily; flurazepam hydrochloride (Dal. mane), $30 \mathrm{mg}$ every night; insulin, 30 U/d (for long-standing diabetes); and naproxen (Naprosyn) for arthritis.

The day you see him, the patient's hematocrit is 0.28 , and the red blood cell indexes indicate a normochromic/normocytic pattern. There is also marked elevation of his alkaline phosphatase, acid phosphatase, and blood glucose levels.

Would you transfuse him at this time?

Four short statements about specific factors that affect indications for trans- 
fusion were also included, with Likert response scales anchored by "strongly disagree" (score of 1) and "strongly agree" (score of 8). Responses to these statements were transformed so that the correct response yielded the higher score. These statements were as follows:

1. A low hematocrit can result in impaired wound healing postoperatively.

2. In general, patients with chronically low hematocrits are less likely to require a red blood cell transfusion than are similar patients with a history of normal hematocrits.

3. Patients with a history of heart disease are more likely to require red blood cell transfusions than are patients with no history of heart disease.

4. A given patient with a hematocrit of 0.40 will feel less fatigued than he or she would with a hematocrit of 0.35 .

A summary knowledge score was created by first standardizing responses to the individual questions ([response mean]/SD) and then summing these values. As a result of this standardization, the contribution to the summary score of questions with different response scales became more comparable than if raw scores had been combined.

Knowledge of Transfusion-Associated Risks. - To assess perceptions of transfusion-associated risks, physicians were asked to read a brief case description and to estimate the probability of each of the following outcomes if a single-unit transfusion were given: the acquired immunodeficiency syndrome (AIDS), symptomatic hepatitis, asymptomatic hepatitis, acute transfusion reaction, and congestive heart failure. They were also asked to estimate the risk of angina or myocardial infarction in the patient described if a transfusion were not given. In addition to point estimates of risk, respondents were asked to provide upper and lower bounds within which they were $95 \%$ certain that the true value lay. Physicians marked their responses to logarithmic scales with probability values ranging from one in 1 million to $100 \%$.

Point estimates were compared with "correct response ranges" bounded by the highest and lowest estimates in the relevant clinical literature. ${ }^{28-36}$ The width of each of these ranges was therefore highly dependent on the degree of scientific consensus as to true risk probabilities. With the exception of congestive heart failure, which was specific to the case presented, these ranges were based on well-designed studies published in the medical literature or on the 1988 National Institutes of Health Consensus Conference statement. ${ }^{5}$ Since the probability of risks due to withholding transfusion were specific to the vignette, ranges for these were based on the judgments of a panel of cardiologists.

To evaluate whether risk estimates were influenced by a clinician's experience (the "availability heuristic"12), we asked physicians to indicate whether they, a colleague in their hospital, or a colleague in another hospital had cared for a patient who developed transfusion-associated AIDS, hepatitis, or a transfusion reaction; the same question was asked about the occurrence of "a negative outcome that might have been avoided by giving a transfusion." Estimates for myocardial infarction were used to assess the influence of the availability heuristic on perceived risks of withholding transfusion.

\section{Measures of Nonclinical Factors}

We measured the importance of peer influence in transfusion decision making by asking physicians how frequently they change their minds about whether to give a patient a transfusion based on the input of colleagues, and whether they believe they have given unnecessary transfusions because of pressure from other physicians.

We also assessed the nature of the influence of attending physicians on residents' transfusion decisions by means of French and Raven's ${ }^{37}$ typology of five sources of power. Residents were presented with statements representing five sources of power described by French and Raven, including expertise, information, referent (normative) power, legitimate authority, and reward/ coercion. They were then asked to indicate the extent to which each of five statements describes their reasoning when they change their minds about giving a patient a transfusion due to input from attending physicians or senior residents. The statements of power were represented as follows:

Expert power: "The attending physician has more experience than I do and is more likely to know the best approach, so I usually follow his or her advice."

Informational power: "The attending physician has helped me understand why it is better to transfuse (or not transfuse) a patient in a given situation."

Referent power: "The attending physician is a talented physician and $I$ make an effort to pattern my practice after him or her as much as possible."

Legitimate power: "The attending physician has ultimate authority over patient care decisions."
Reward/coercive power: "The attending physician has the ability to make my life difficult, so it is best to go along with his or her opinion."

To address the importance of patient preference in transfusion decision making, physicians were asked the extent to which patient preference or concern should, and actually does, influence their transfusion decisions (1, "not at all," to 8, "a great deal"). Respondents" estimates of the cost to the hospital of administering $1 \mathrm{U}$ of red blood cells were compared with an estimate of actual transfusion cost. Similar questions assessed perceptions of the availability of blood products and awareness of guidelines for transfusion practice in the hospital, as well as the extent to which cost, availability, and guidelines shape their transfusion decisions (1, "not at all," to 8, "a great deal").

Evaluation of practice style included measures of confidence and interventionism. "Confidence" was represented by the degree of physician certainty about transfusion risk probabilities. Since risk estimates were given in response to a standard case description, this measure is a reflection of physicians' certainty about the risks rather than variation in risk related to specific patient characteristics. Confidence ranges for each risk were estimated as the difference between the log of the upper and lower confidence bounds, with a narrower range (lower score) indicating greater physician confidence. A confidence score was calculated for each physician as the mean confidence range across all risk estimates given by that physician.

Physicians' interventionist tendencies were evaluated by using a hypothetical clinical vignette in which the expected risks and benefits to the patient were identical whether or not a red blood cell transfusion was given. The interviewer emphasized that in the vignette the probabilities of all possible morbidity, mortality, and "quality of life" states were the same regardless of the treatment option. Physicians were then asked to make a transfusion decision and provide the rationale for their decision. The vignette was as follows:

Imagine that it is the year 2000 , and all current adverse effects of blood transfusion have been eliminated through a variety of screening tests, except for one. This is a newly described acute hemolytic reaction that occurs completely unpredictably with $3 \%$ of transfused units. Fifty percent of patients experiencing this reaction die within a few days, and 50\% will recover fully with only minor sequelae. 
Assume further that by the year 2000 a vast computer bank has been established such that it is possible to predict with a good degree of certainty the outcomes of various clinical decisions. For a particular patient under your care with a history of heart disease and a low hematocrit, you learn that if a transfusion is not given, there is a $3 \%$ risk of myocardial infarction. The computer further indicates that the myocardial infarction, if it occurs, will have a 50\% chance of being fatal and that there is likewise a 50\% chance that the patient will recover fully from it with only minor sequelae. If the patient is transfused, the risk of myocardial infarction would drop to zero.

This patient's risk of death is identical whether or not a transfusion is given. Assuming that the mode of death in either case is swift and not particularly gruesome, and assuming that the morbidity and implications of the minor sequelae in each case are quite comparable, would you or would you not transfuse this patient?

\section{Statistical Analyses}

Pearson's correlations, analysis of variance, and least-squares multiple regression were used to assess relationships among hospital, specialty, years of practice, and continuous outcome variables, including knowledge and risk scores, peer influence, and confidence. Wilcoxon's Rank-Sum tests were conducted to evaluate differences in risk estimate distributions among physicians with different levels of personal experience with transfusion-related morbidity; a test based on medians was used to avoid the overinfluence of a few extreme estimates. The $\chi^{2}$ test was used to assess variation in nonclinical influences by hospital and specialty for most eight-point response scale questions; some scales were collapsed into four groups to avoid small cell counts.

\section{RESULTS}

We completed interviews with 122 physicians, including 76 surgeons and 46 anesthesiologists. Fifty of the physicians interviewed were attending physicians and 72 were residents. The sample included 51 physicians from hospital A, 32 from hospital B, and 39 from hospital $\mathrm{C}$. The overall response rate was $91 \%$.

\section{Knowledge of Transfusion Indications and Risks}

Deficiencies in knowledge of transfusion indications were widespread. Most physicians $(97.5 \%)$ correctly mentioned the hematocrit or hemoglobin as a factor to be considered in response to the deci-

Table 1.-Mean Summary Knowledge Scores by Hospital, Specialty, and Years of Practice

\begin{tabular}{lcc}
\hline & N & $\begin{array}{c}\text { Mean Summary Knowledge Score } \\
\text { (Range, - 11.54-6.32) }\end{array}$ \\
\hline $\begin{array}{l}\text { Hospital* } \\
\text { A (primary teaching) }\end{array}$ & 51 & 0.50 \\
\hline \begin{tabular}{l} 
B (municipal) \\
\hline (secondary teaching)
\end{tabular} & 32 & 0.89 \\
\hline $\begin{array}{l}\text { Specialty } \\
\text { Surgery }\end{array}$ & 39 & -1.40 \\
\hline Anesthesiology & 76 & 0.01 \\
\hline $\begin{array}{l}\text { Physician rankt } \\
\text { Resident }\end{array}$ & 46 & -0.01 \\
\hline $\begin{array}{l}\text { Attending } \\
\leq 20 \text { y of practice }\end{array}$ & 72 & 0.80 \\
\hline$>20$ y of practice & 29 & -0.28 \\
\hline
\end{tabular}

*Analysis of variance, $P \leq .01$

tAnalysis of variance, $P \leq .001$

sion component question. However, only $55 \%$ mentioned the presence or absence of heart disease, and half of these listed only "history of heart disease," despite the prompt described above. The mean decision component score was 2.8 (range, 0 to 4 ).

Half of the physicians ( $53 \%$ ) correctly indicated that they would not give transfusions to any of the four patients in the case vignettes. The proportion of incorrect responses ranged from a low of $8 \%$ in a case describing a preoperative patient undergoing hip repair with a hematocrit of 0.33 , to a high of $25 \%$ for a description of a terminal cancer patient with a long-term hematocrit of 0.28 , whose weakness was likely attributable to multiple sedative drugs rather than anemia.

Only $31 \%$ of physicians answered all four short questions correctly. The proportion of incorrect answers to the short questions ranged from $11 \%$ to $41 \%$ (incorrect, 1 to 4 on an 8-point scale). Forty-one percent of physicians incorrectly indicated that a low hematocrit can itself result in impaired postoperative wound healing.

Table 1 presents analysis of variance results and mean values for the standardized summary knowledge score by hospital, specialty, and years of practice (physician rank). The values of the standardized knowledge score ranged between -11.54 and 6.32. Physicians in hospitals A (primary teaching) and B (municipal with residents rotating from a primary teaching hospital) had higher knowledge scores, on the average, than did those in hospital C (secondary teaching) $(P<.01)$. A strong negative association was noted between years of practice and the knowledge score, with older physicians scoring significantly lower than younger ones $(P<.001)$. The mean summary knowledge score was 0.80 for residents, compared with -0.28 and -2.35 for attending physicians with less than or greater than 20 years of practice, respectively. The standardized $\beta$ coefficient of the summary knowledge score regressed on years of practice as a continuous variable was -0.34 and was significant at $\alpha=.0001$.

Figures 1 and 2 present the distributions of risk estimates in relation to correct response ranges. Each transfusionassociated risk was incorrectly estimated by more than half of the physicians, when compared with the range of probabilities presented in the clinical literature (Fig 1). Many markedly overestimated the probability of transfusion-associate AIDS; $52 \%$ were above the range indicated in the literature. Although estimates near but outside the correct response range may not be cognitively different from those just within these bounds, fully $24 \%$ of responses were at least 10 times higher than the upper bound of 1/40000 units. A somewhat higher percentage of physicians gave correct estimates of the risks of withholding transfusion in the vignette presented, compared with the range of expert estimates (Fig 2). "Accuracy" of physicians' risk estimates related to withholding transfusion were in part a function of the degree of expert agreement. High agreement was noted among the experts as to the risk of myocardial infarction (range, $1 \%$ to $5 \%$; mean, $4 \%$ ), whereas the range for angina was substantially wider due to a high estimate by one physician (range, $5 \%$ to $40 \%$; mean, $18 \%$ ). The risk of myocardial infarction was overestimated by $48 \%$ of responding physicians, whereas a smaller percentage $(23 \%)$ overestimated the risk of angina. There was more overestimation than underestimation of both transfusion and nontransfusion risks.

\section{Personal Experience and Risk Estimates}

Physicians who reported having personally treated a patient who suffered an adverse outcome that might have 


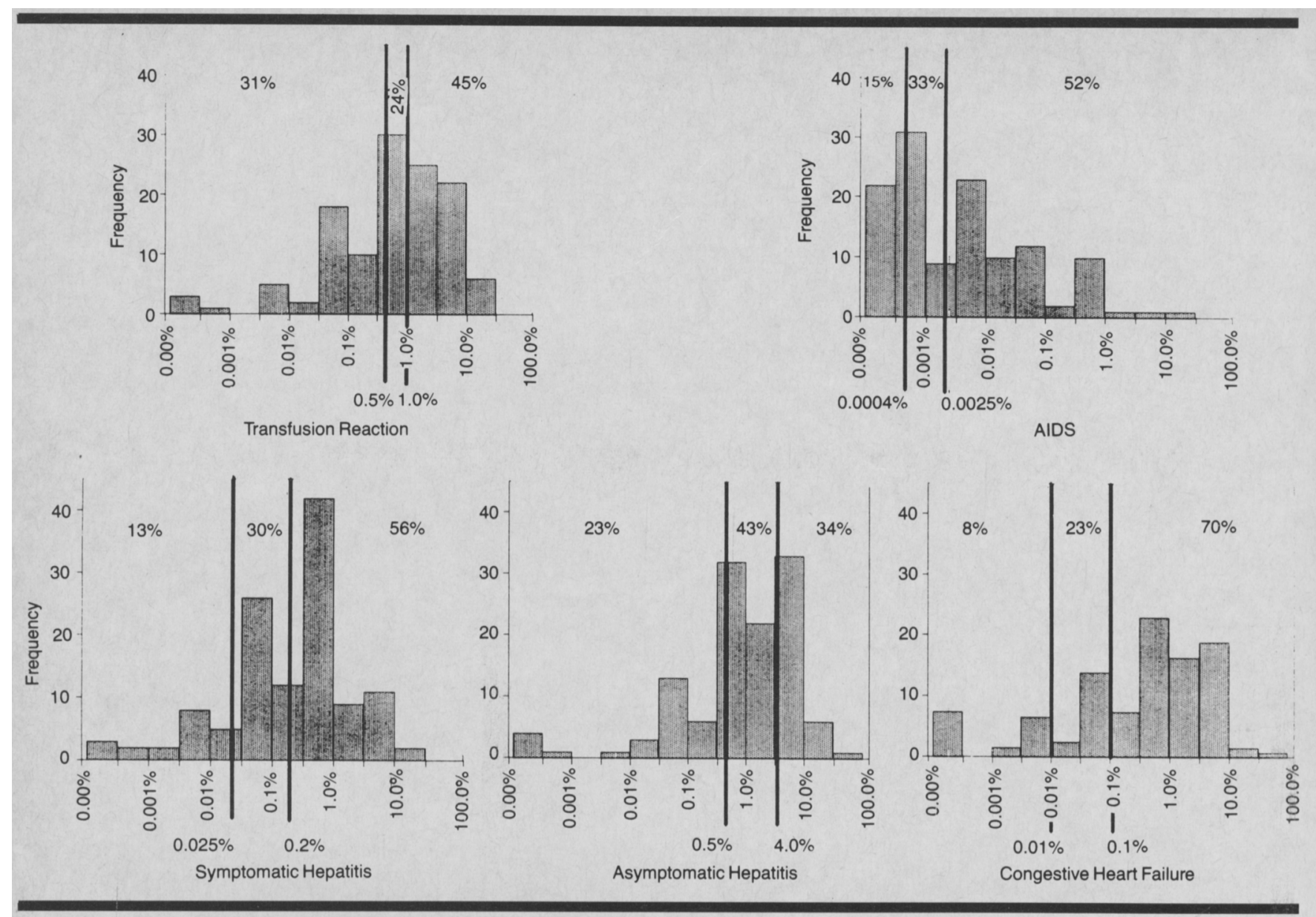

Fig 1. - Distribution of physicians' estimates of risks associated with giving a single-unit red blood cell transfusion. Bold lines indicate upper and lower bounds of correct response range according to the clinical literature. AIDS indicates the acquired immunodeficiency syndrome.

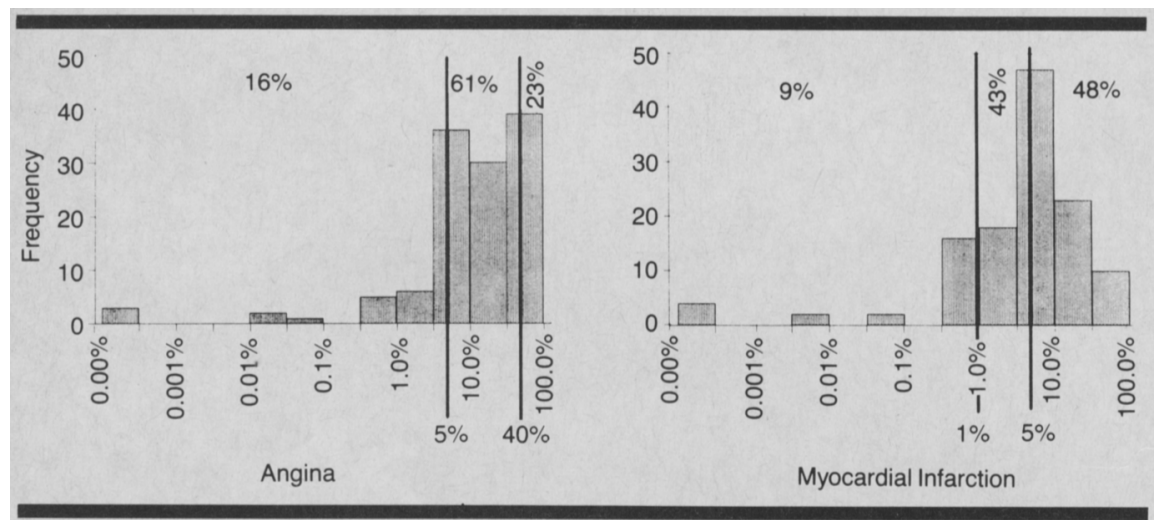

Fig 2. - Distribution of physicians' estimates of risks associated with withholding a transfusion from a patient described in a case vignette. Bold lines indicate upper and lower bounds of correct response range according to a panel of experts.

been prevented by a transfusion gave estimates of the risk of myocardial infarction (if transfusion were withheld) twice as high as those given by physicians without such personal experience (medians, 10\% and 5\%, respectively; $P=.03)$. There were no significant differences in estimates of posttransfusion AIDS, hepatitis, or transfusion reaction between groups of physicians according to the intimacy of their experience with these outcomes. Thus, perceptions of risks of withholding a potentially necessary transfusion seem to be influenced by physicians' personal experience, whereas perceptions of transfusion risks are independent of such experience.

\section{Peer Influence}

Many respondents acknowledged the importance of collegial influence on their transfusion decision making. Half of all attending physicians reported that they change their mind about whether or not to give a patient a transfusion based on the input of colleagues at least once a month. Only $10 \%$, however, stated that they had given a potentially unnecessary transfusion to appease a colleague once a month or more (Table 2). Among attending physicians, responses to these questions did not vary by hospital, specialty, or years of practice.

In contrast, residents reported being strongly influenced by other physicians. Sixty-eight percent indicated that their transfusion decisions vary with the attending physician (response, 5 to 8 , where 1 indicates "not at all" and 8, "a great deal"). Residents at the primary teaching hospital (A) were more highly influenced than those at either the municipal (B) or secondary teaching (C) hospital (means, 6.6, 3.9, and 4.8, respectively; $P=.0001$ [A vs $\mathrm{B}$ ] and $P=.02$ [A vs C]). More than three quar- 
Table 2.-Percentage of Physicians Who Reported That They Give Unnecessary Transfusions Because Another Physician Suggested That They Do So

\begin{tabular}{|c|c|c|}
\hline & \multicolumn{2}{|c|}{$\%$} \\
\hline & $\begin{array}{l}\text { Attending } \\
\text { Physicians } \\
(\mathrm{N}=49)\end{array}$ & $\begin{array}{c}\text { Residents } \\
(\mathbf{N}=71)\end{array}$ \\
\hline Very trequently (aboul once a week) & 2.0 & 2.8 \\
\hline Frequently (about once every 2 wk) & 2.0 & 18.3 \\
\hline Occasionally (about once a month) & 6.1 & 39.4 \\
\hline Rarely (about once every 2 mo or less) & 63.3 & 32.4 \\
\hline Never & 26.5 & 7.0 \\
\hline
\end{tabular}

Table 3. - Extent of Influence of Five Sources of Power on Residents' Tranfusion Decisions $(N=72)$

\begin{tabular}{lccccc}
\hline \multirow{2}{*}{$\begin{array}{c}\text { Likert Scale } \\
\text { Response }\end{array}$} & Expert & Information & Referent & Legitimate & Coercive \\
\hline $1-2$ (not at all) & 15.3 & 19.5 & 33.3 & 4.2 & 41.6 \\
\hline $3-4$ & 18.0 & 20.8 & 29.1 & 7.0 & 15.2 \\
\hline $5-6$ & 44.5 & 36.1 & 33.3 & 13.9 & 26.3 \\
\hline $7-8$ (a great deal) & 22.2 & 22.2 & 4.2 & 75.0 & 19.4 \\
\hline Mean response & 5.1 & 4.8 & 3.6 & 6.8 & 4.0 \\
\hline
\end{tabular}

Table 4. - Perceived Influence of Patient Concern, Cost, Blood Availability, and Transfusion Guidelines on Transfusion Decision Making

\begin{tabular}{|c|c|c|c|c|}
\hline \multirow[b]{2}{*}{ Response } & \multicolumn{4}{|c|}{$\%$} \\
\hline & $\begin{array}{l}\text { Patient } \\
\text { Concern } \\
(N=122)\end{array}$ & $\begin{array}{c}\text { Cost } \\
(N=122)\end{array}$ & $\begin{array}{l}\text { Availability } \\
(\mathrm{N}=122)\end{array}$ & $\begin{array}{l}\text { Guidelines } \\
(N=67)\end{array}$ \\
\hline $1-2$ (not at all) & 25 & 86 & 46 & 46 \\
\hline $3-4$ & 24 & 12 & 19 & 25 \\
\hline $5-6$ & 29 & 4 & 24 & 18 \\
\hline 7-8 (a great deal) & 23 & 0 & 11 & 10 \\
\hline Mean response & 4.6 & 1.6 & 3.5 & 3.3 \\
\hline
\end{tabular}

ters of all residents $(77 \%)$ indicated that they changed their transfusion decisions once a month or more based on the input of colleagues. This occurred more frequently at hospitals $\mathrm{A}$ and $\mathrm{B}$ than at hospital $\mathrm{C}(79 \%, 70 \%$, and $48 \%$, respectively). Fully $61 \%$ of residents indicated that they had given transfusions that they thought were unnecessary because a more senior physician had suggested that they do so, at least once a month (Table 2). One third of these ( $21 \%$ of the sample) reported this occurring twice a month or more. The responses to this question did not vary systematically by year of postgraduate training, hospital, or specialty.

Table 3 presents responses describing the source of influence of attending physicians on residents' decision making. Overwhelmingly, residents reported being influenced by the legitimate authority of the attending physician. Three quarters indicated that this attribute influenced them a great deal, and only $4 \%$ believed that the authority of the attending physician had little or no influence. Smaller per- centages ( $19 \%$ to $22 \%$ ) reported being strongly influenced by the coercive, expert, and informational power of attending physicians.

\section{Patient Preference}

On average, physicians stated that half of the patients for whom they order a red blood cell transfusion voice concern about the risks of transfusion; $21 \%$ reported that more than four fifths of their patients voice concern. Most physicians $(85 \%)$ believed that patient's desires should be considered when deciding whether or not to order a red blood cell transfusion (response, 5 to 8 ), and many $(53 \%)$ strongly agreed with that statement (response, 7 to 8). Yet, when asked the extent to which patient concern actually influences their transfusion decisions, $52 \%$ indicated that they were affected at all by patient preferences, and only $23 \%$ indicated that their decisions were greatly influenced (Table 4).

\section{Blood Product Cost}

Fewer than half of the physicians (44\%) estimated the cost of red blood cells within $50 \%$ above or below the true cost approximation of $\$ 100$ ( $\$ 50$ to $\$ 150$ ). Similar proportions estimated costs below and above this range ( $25 \%$ and $30 \%$ ). Most (86\%) indicated that cost considerations played little or no role in their transfusion decision making; no physician thought that cost was an important consideration in transfusion decision making (Table 4). No differences were noted in perceptions of the influence of cost by hospital, specialty, or years of practice.

\section{Availability of Blood Products}

Physicians were asked to characterize the current availability of blood products by selecting one of four descriptions ranging from "no current shortage with no concern about afuture shortage" to "a current shortage such that blood might not always be available when needed." Seventy-eight percent perceived some shortage of blood products, and slightly under half of these believed that blood products might not be available when needed sometime in the future. Older physicians were less likely to perceive a shortage of blood products than were their younger colleagues. Only $16 \%$ of residents selected one of the two descriptions suggesting no current shortage, compared with $21 \%$ of attending physicians with 20 years of practice or less and $40 \%$ of those who had practiced for more than 20 years $(P=.03)$. Almost half of the physicians indicated that they were influenced little or not at all by perceptions of availability; only $11 \%$ reported that their decisions were greatly affected by the availability of blood products (Table 4).

\section{Transfusion Guidelines}

Almost half of the physicians surveyed $(44 \%)$ indicated no awareness of guidelines set down by the blood bank or hospital administration regarding the ordering and transfusion of blood products. This did not vary substantially by hospital, specialty, or years of practice. Of those physicians who indicated an awareness of guidelines, $46 \%$ reported that these guidelines had little or no influence on their transfusion decisions (Table 4). When added to those physicians who indicated no awareness of transfusion guidelines, $70 \%$ of all physicians surveyed were unaffected by transfusion guidelines.

\section{Practice Style: Confidence and Interventionism}

The measure of confidence was negatively associated with the summa- 
ry knowledge score $(\beta=.22, P=.02)$. That is, physicians with the least knowledge demonstrated the greatest confidence. Attending physicians demonstrated significantly more confidence than did residents (medians, .54 and .78, respectively), with a lower score indicating greater confidence $(P=.03)$. Because of the negative association between knowledge and years of practice (older physicians also had lower knowledge scores), the influence of these two factors was examined in a multivariate regression model. The effect size for each of the two variables was somewhat smaller than in the single-variable regression models, and the $P$ values approached but did not reach statistical significance (physician rank: $\beta=.15$, $P=.12$; knowledge: $\beta=.18, P=.06$ ) There was no association between confidence and accuracy of risk estimates.

In response to the hypothetical vignette in which the probabilities of all patient outcomes were identical if a transfusion was administered or withheld, $70 \%$ of respondents $(n=85)$ stated that they would not give the patient a transfusion (noninterventionist). Of these, $76 \%(n=60)$ explained their reasoning with a version of the traditional injunction "First do no harm." Despite the instructions, 9\% insisted on inferring differences in patient outcomes (ie, a transfusion reaction is worse than a myocardial infarction), $5 \%$ voiced concerns about malpractice, and $4 \%$ mentioned cost as a factor motivating their decision. Of the 28 physicians (30\%) choosing to give the hypothetical patient a transfusion, $78 \%$ related a philosophy of a preference to treat, indicating that they should do everything they could for the patient ("First do something"). An additional $14 \%$ insisted on inferring differences in patient outcomes (ie, a myocardial infarction is worse than a transfusion reaction). These responses suggest that the transfusion decisions in this case are largely a reflection of general interventionist or noninterventionist tendencies in these physicians.

\section{COMMENT}

The results of this survey highlight the importance of simultaneously studying clinical knowledge, physician characteristics, and the context of the practice setting as influences on physician decision making. We observed gaps in physicians' knowledge of the indications for and the risks of blood transfusion. The negative association between knowledge and years of practice may be partially explained by the recent increased emphasis on transfusion medi- cine in the clinical curriculum. Lower knowledge scores by older physicians may also be due in part to cognitive dissonance; less attention is given to information that is inconsistent with their current beliefs. Thus, wellestablished practice strategies may not be appropriately revised as new information becomes available. This hypothesis is supported by the observed association between confidence and years of practice.

We were surprised by the degree to which physicians incorrectly estimated transfusion-associated risks, given our intention of defining generous correct response ranges. This suggests that to the extent that inappropriate transfusion practice is a function of risk perceptions, it is more likely to be a function of overconcern about negative outcomes due to withholding transfusion, rather than reduced concern over transfusionassociated risks. This is reflected both in the tendency of physicians to overestimate rather than underestimate transfusion risks and in the lack of impact of experiences with adverse transfusion-associated outcomes on physicians' risk estimates. The influence of personal experience only on risks of nontransfusion is also consistent with the hypothesis that in this domain, physicians may be more concerned about errors of omission than errors of commission.

Attending physicians consider the input of their peers but rarely report acting against their own clinical judgment. It is possible that this phenomenon was underreported because of the undesirability of admitting to such influence. Residents, however, freely reported the extent to which senior physicians influenced their decisions. The high proportion of residents who reported ordering transfusions that they judged unnecessary because of perceived pressure from attending physicians, together with the negative relationship between years of practice and transfusionrelated knowledge, suggests that for resident physicians such pressure may at times be more influential than their own evaluation of the clinical facts

The finding that residents responded primarily to the legitimate authority of attending physicians is consistent with descriptions of decision making on surgical services as hierarchically structured; decisions are handed down from attending physicians to chief or senior residents, and on to subordinate residents. ${ }^{38+40}$ Although authoritarian decision making may be well suited to some aspects of surgical work, ${ }^{38,39,41}$ it may be dysfunctional in the case of transfusion practice, given the differences we have observed in transfusion-related knowledge.

Many physicians reported that they should, and do, consider patient preferences when making transfusion decisions. This finding is consistent with the literature in other domains of medical care. ${ }^{12}$ With increased patient concern over the highly publicized risk of AIDS, the move toward informed consent for blood transfusion has further heightened this issue. Physician responses to patient preference may also be closely linked with increased concerns about malpractice in the event of an adverse outcome. Consistent with most of the literature to date, we found that physicians place little or no emphasis on cost in their transfusion decisions. ${ }^{21,43,44}$ Blood product availability and hospital guidelines are also perceived as having little influence.

The findings of this analysis can be used to guide both the content and the process of intervention strategies to improve blood product use. There is clearly a need for a scientifically based educational component focusing on the indications for transfusion. Providing physicians with an update of rapidly changing estimates of important transfusion risks is essential. Such information alone, however, may not reduce unnecessary blood product use, since these risks already tend to be overestimated. Risks associated with withholding transfusion were also more likely to be overestimated. Therefore, educating physicians about the physiology of oxygen transport, so that they better understand the point at which the patient's condition is truly compromised by anemia, has greater potential for improving transfusion decision making. Given the increased levels of confidence found in older physicians, the involvement of a respected colleague or opinion leader may play an important role in encouraging them to be receptive to new information and to consider modifying the decision strategies on which they base their practice. They will, however, most likely need to be convinced on the strength of clinical evidence to make lasting prac-

Although residents should be provided with an update of the current clinical standards regarding transfusion risks and indications, the findings of this analysis suggest that the most effective way to modify their transfusion practice is by changing the attitudes and decision-making strategies of attending physicians. Ideally, residents would then provide care that both meets the demands of the attending physician and is in keeping with their own clinical judgment. 
A number of intervention strategies might be combined to improve transfusion practices. Face-to-face educational sessions with individual physicians by either an outside expert or inside opinion leader have been effective in reducing inappropriate resource use..$^{10,45,46}$ Educational efforts may also be coupled with an administrative intervention. ${ }^{47,46}$ Order forms might include information with a checklist regarding transfusion indications and risks. In settings in which order entry is available, such systems may be interactive and computerized. Any strategy chosen is more likely to be effective if the nonclinical factors and relationships examined above are acknowledged and incorporated into the intervention. This approach is supported by the observation that the most successful education-based interventions have included the participation of clinical leaders, thus providing social reinforcement for the educational message. ${ }^{6,10,45}$

Although this survey was limited to a single clinical decision, many of its findings may be generalizable to efforts to improve the use of other resources. The negative association between knowledge and years of practice is consistent with findings from other studies. ${ }^{6}$ The influential relationship observed between attending surgeons and anesthesiologists and their residents certainly extends beyond the use of blood products, although it may vary between clinical specialties. Differences in decisionmaking styles between physicians on medical and surgical services suggest that different strategies may be effective in motivating practice changes among these groups. As continued research leads to an improved under- standing of the specific influences on medical decision making for different groups of physicians in a variety of practice settings, the ability to develop effective practice change strategies and consequent improvements in the quality of care will also be advanced.

This study was supported by grant HS 05300 from the National Center for Health Services Research, Rockville, Md.

We wish to thank Paul Cleary, $\mathrm{PhD}$, and $\mathrm{R}$. Heather Palmer, MB, BCh, SM, for their invaluable input into the design and analysis of the survey and for their heipful comments on drafts of this article. We are grateful to Harold Kaplan, MD, Margo Kruskall, MD, Johanna Pindyck, MD, Mark Popovsky, MD, Robert Reiss, MD, Robert Thurer MD, and Carl Wolf, MD, for their guidance and expertise on clinical issues and treatment guidelines in transfusion medicine. We would also like to thank Marietta Abrams for help in conducting interviews and Tina Casteris and Susanne Bellevance for assistance with data processing.

\section{References}

1. Palermo G, Bove J, Katz AJ. Patterns of blood use in Connecticut. Transfusion. 1980;20:704-710. 2. Tartter PI, Barron DM. Unnecessary blood transfusion in elective colorectal cancer surgery Transfusion. 1985;25:113-115.

3. Blumberg N, Laczom A, McMican A, et al. A critical survey of fresh-frozen plasma use. Transfu sion. 1986;26:511-513.

4. Brien WF, Butler RJ, Inwood MJ. An audit of blood component therapy in a Canadian genera teaching hospital. Can Med Assoc J. 1989;140:812815.

5. Perioperative Red Cell Transfusion. Consensus Development Conference 5.5. statement. Bethesda, Md: National Institutes of Health; 1988;7:4 6. Eisenberg JM. Doctors' Decisions and the Cost of Medical Care. Ann Arbor, Mich: Health Administration Press; 1986.

7. Williams SV, Eisenberg JM, Pascale LA, Kit DS. Physicians' perceptions about unnecessary diagnostic testing. Inquiry. 1982;19:363-370.

8. Eisenberg JM. Sociologic influences on decision making by clinicians. Ann Intern Med. 1979;90. 957-964.

9. Anderson OW, Shields MC. Quality measure ment and control in physician decision making state of the art. Health Serv Res. 1982;17:125-155.

10. Soumerai SB, Avorn J. Efficacy and cost-containment in hospital pharmacotherapy: state of the art and future directons. Milbank Mem Fund $Q$ Health Soc. 1984;62:3.

11. Einhorn HJ. Learning from experience and suboptimal rules in decision processes. In: Wallsten TS, ed. Cognitive Processes in Choice Decision Behavior. Hillsdale, NJ: Lawrence Erlbaum Assoc; 1980:1-20.

12. Tversky A, Kahneman D. Judgement under uncertainty: heuristics and biases. Science, 1984, 185:1124-1131.

13. Slovic P, Fischoff B, Lichtenstein S. Response mode, framing and information processing effect in risk assessment. In: Hogarth $\mathrm{R}$, ed. New Directions for Methodology of Social and Behaviora Science: Question Framing and Response Consis tency. San Francisco, Calif: Jossey Bass Inc Publishers; 1982;11:21-36.

14. Tversky A, Kahneman D. Availability: a heuristic for judging frequency and probability. Cognitive Psychol. 1973;5:207-232.

5. Coleman JS, Menzel H, Katz E. Social processes in physicians' adoption of a new drug. $J$ Chronic Dis. $1959 ; 9: 1-19$.

16. Williamson PM. The adoption of new drugs by doctors prescribing in group and solo practice. Soc
Sci Med. 1975;9:223-236.

17. Weinberg AD, Ullian L, Richards W, Cooper P. Informal advice and information seeking between physicians. J Med Educ. 1981;56:174-180.

18. Myers LP, Schroeder S. Physician use of services for the hospitalized patient: a review with implications for cost containment. Milbank Mem Fund Q Health Soc. 1981;59:481-507.

19. Berner E, Coulson L, Schmitt B. A method to determine attitudes of faculty members toward use of laboratory tests. J Med Educ. 1985;60:374-378. 20. Schroeder SA. Variations in physician practice patterns: a review of medical cost implications. In Carols EJ, Neubauser D, Stason WB, eds. The Physician and Cost Control. Cambridge, Mass: Oelgeschlager Gunn and Hain; 1980:23-50.

21. Segal R, Hepler DC. Drug choice as a problem solving process. Med Care. 1985;23:967-976.

22. Epstein AM, McNeil BJ. Relationship of belief and behavior in test ordering. Am $J \mathrm{Med}$. 1986; 80:865-870.

23. Campbell DM. Why do physicians in neonatal care units differ in their admission thresholds? Soc Sci Med. 1984;18:365-374

24. Brett AS. Hidden ethical issues in clinical decision analysis. $N$ Engl J Med. 1981;305:1150-1152.

25. Haney CA. Psychosocial factors involved in medical decision making. In: Millon T, ed. Medical Behavioral Science. Philadelphia, Pa: WB Saunders Co; 1975:420-432.

26. Ellsberg D. Risk, ambiguity and the Savage axioms. $Q J$ Econ. 1961:75:643-669.

27. Curley S, Eraker SA, Yates JF. Psychological sources of ambiguity avoidance. Organ Behav Hum Decis Proc. 1986;38:230-256.

28. Ward JW, Holmberg SD, Allen JR, et al. Trans mission of human immunodefiency virus (HIV) by blood transfusions screened as negative for HIV antibody. N Engl J Med. 1988;318:473-478.

29. Kleinman S, Secord K. Risk of human immunodeficiency virus (HIV) transmission by anti-HIV negative blood: estimates using the lookback methodology. Transfusion. 1988;318:499-501.

30. Bove JR. Transfusion-associated hepatitis and AIDS: what is the risk? $N$ Engl $J$ Med. 1987;317:242-245.

31. Aach RD, Szmuness W, Mosley JW, et al. Se rum alanine aminotransferase of donors in relation to the risk of non-A non-B hepatitis in recipients: the transfusion-transmitted viruses study. $N E n g l$ IMed. 1981;304:989-994

32. Alter HJ, Purcell RH, Holland PV, et al. Donor transaminase and recipient hepatitis: impact of blood transfusion services. JAMA. 1981;246:
630-634.

33. Holland PV. Risks of red cell transfusion: overview and perspective. In: Perioperative Red Cell Transfusion. Consensus Development Conference Program and Abstracts. Bethesda, Md: National Institutes of Health; 1988:83-86.

34. Walker RH. Transfusion risks. Am J Clin Pathol. 1987;88:374-378.

35. Carlson DA. The role of the blood bank medica director in patient care. Hosp Pract. 1985:20:24-30. 36. Popovsky MA, Taswell HS. Circulatory overload: an underdiagnosed consequence of transfusion. Transfusion. 1985;5:469.

37. French JRP Jr, Raven BH. The bases of socia power. In: Cartwright D, ed. Studies in Socia Power. Ann Arbor, Mich: Institute for Social Research, University of Michigan; 1959:150-167.

38. Coser RL. Authority and decision-making in hospital: a comparative analysis. Am Soc Rev. 1958;23:56-64.

39. Knafl K, Burkett G. Professional socialization in a surgical speciaity: acquiring medical judgment. Soc Sci Med. 1975;9:397-404.

40. Eisenberg JM, Kitz DS, Webber RA. Development of attitudes about sharing decision-making: a comparison of medical and surgical residents. $J$ Health Soc Behav. 1983;24:85-90.

41. Bosk CL. Forgive and Remember: Managing Medical Failure. Chicago, Ill: University of Chicago Press; 1979

42. Schwartz RK, Soumerai SB, Avorn J. Physician motivations for nonscientific drug prescribing. Soc Sci Med. 1989;28:577-582.

43. Skipper JK, Smith G, Mulligan JL, Gary ML. Physicians' knowledge of cost: the case of diagnostic tests. Inquiry. 1976;8:194-198.

44. Nagurney JT, Braham RL, Redder G. Physician awareness of economic factors in clinical decision making. Med Care. 1979;17:727-736.

45. Soumerai SB, McLaughlin T. Improving drug prescribing in primary care: a critical analysis of the experimental literature. Milbank Q. 1989;67:268317

46. Stross JK, Bole GC. Evaluation of a continuing education program in rheumatoid arthritis. Arthri tis Rheum. 1986;23:846-849.

47. Avorn J, Soumerai SB, Taylor W, Wessels MR Janousek J, Weiner M. Reduction of incorrect antibiotic dosing through a structured educational order form. Arch Intern Med. 1988;148:1720-1724.

48. Buchwald D, Soumerai SB, Vandevanter N Wessels MR, Avorn J. Effect of hospitalwide change in clindamycin dosing schedule on clinical outcome. Rev Infect Dis. 1989;2:619-624. 